\title{
Attitudes of Physicians to the Policy of Mandatory Use of Chaperone in Clinical Practice
}

\author{
Onyiaorah $\mathrm{IV}^{1}$, Eleje $\mathrm{GU}^{\star 2}$, Nwankwo $\mathrm{KC}^{3}$, Ikechebelu $\mathrm{JI}^{2}$, Joe-Ikechebelu $\mathrm{NN}^{4}$ and Edene $\mathrm{CN}^{5}$ \\ ${ }^{1}$ Department of Histopathology, Nnamdi Azikiwe University, Nnewi Campus, PMB 5001, Nnewi, Anambra State, \\ Nigeria \\ ${ }^{2}$ Department of Obstetrics \& Gynecology, Faculty of Medicine, College of Health Sciences, Nnamdi Azikiwe \\ University, Nnewi Campus, PMB 5001, Nnewi, Anambra State, Nigeria \\ ${ }^{3}$ Department of Radiation Medicine, University of Nigeria, Enugu Campus, Enugu, Enugu State, Nigeria \\ ${ }^{4}$ Department of Community Medicine, Chukwuemeka Odumegwu Ojukwu University, Amaku, Awka \\ ${ }^{5}$ Department of Obstetrics and Gynaecology, Federal Teaching Hospital, Abakaliki, Ebonyi State, Nigeria
}

${ }^{*}$ Corresponding author: Eleje GU, Department of Obstetrics \& Gynecology, Faculty of Medicine, College of Health Sciences, Nnamdi Azikiwe University, Nnewi Campus, PMB 5025, Nnewi, Anambra State, Nigeria, Tel: +2348068117444, E-mail: georgel21@yahoo.com

Citation: Onyiaorah IV, Eleje GU, Nwankwo KC, Ikechebelu JI, Joe-Ikechebelu NN, et al. (2016) Attitudes of Physicians to the Policy of Mandatory Use of Chaperone in Clinical Practice. J Gynecol Res 2(1): 102. doi: $10.15744 / 2454-3284.2 .102$

Received Date: August 29, 2016 Accepted Date: October 26, 2016 Published Date: October 27, 2016

\begin{abstract}
Objectives: This study determines the attitudes and current practices of physicians regarding the use of chaperones in their daily clinical practice.

Methods: A multi-centered study in four tertiary hospitals in Nigeria involving self-administered questionnaire of physicians in various medical disciplines was done. Main outcome measures were frequency of chaperone use, respondents' views on mandatory chaperone use policy, preferred gender for the role of chaperone and main factors influencing the physicians' attitude. Bivariate analyses were conducted.

Results: Of the 200 questionnaires distributed, 150 (75.0\%) were returned. Majority, 74.4\% recommended mandatory chaperone policy while $73.6 \%$ had never or occasionally used chaperone in their practice. The use of chaperones correlated with physicians' age $(\mathrm{p}<0.05)$ but not with gender and years of practice. Although, majority, $73.6 \%$ preferred gender-specific chaperone, cross gender policy $49.2 \%$ was the most preference. Majority (94.4\%) believed that whole body parts and/or breast and pelvic examination required mandatory chaperone policy implementation.

Conclusions: Majority of physicians either had never or occasionally used chaperones in their practice. However, most agreed that presence of chaperone had been useful in their practice with higher predilection to cross gender policy.

Keywords: Chaperone; Policy; Gender; Physician; Clinical Practice
\end{abstract}

\section{Introduction}

Medical chaperones are persons, often health professionals that act as third-party observers during certain clinical examinations especially intimate examinations, either at the request of the patient or due to the doctor's clinical discretion [1,2]. Such use of chaperone during intimate physical examination has been recommended as a standard practice by many medical professional organizations and regulatory bodies worldwide [3-5]. The goal of medical chaperoning is to protect the patient from possible inappropriate behaviours from the physician including sexual abuse or exploitation [6-8]. It may also serve as a sign of respect for the patients and an appropriate chaperone may also protect healthcare practitioners from false accusations [9].

In recent years, there has been an increasing call by medico-legal societies and medical insurance companies for greater use of chaperones during intimate examinations [10]. Despite this trend, the frequency of chaperone use has generally remained low especially in Nigeria [3,11]. This may be because; as yet the Nigerian Code of Medical Council does not have a policy on mandatory chaperone use in medical consultation [11]. 
Several surveys have shown the difficulties amongst medical practitioners in embracing mandatory chaperone policies. Apart from the issues relating to doctor-patient communication and patients confidentiality, the cost and availability of medical chaperones constitute an overwhelming challenge for chaperoning in our clinical practice. In view of these logistic problems, a policy that requires chaperone at every examination for every patient may not be feasible and is as such inadvisable [9,11]. Limiting the compulsory use of chaperone to specific intimate physical examination and always giving the patient the opportunity to choose may well be the more acceptable and practicable option to follow in clinical practice.

Additionally, previous published studies on the use of chaperone in Nigeria have focused exclusively either on assessing the opinions, attitude, and preferences of women to the presence of chaperones during pelvic examinations or attitudes of a particular medical discipline such as gynaecologist or general practitioners to medical chaperoning $[3,11,12]$. In one of these studies, scarcity of personnel to serve as chaperones is the greatest challenge to the implementation of this policy. Notwithstanding, the views and attitudes of physicians in other disciplines toward the use of chaperone in medical practice have remained un-investigated [11]. This study therefore explored the attitudes and current practices of a cohort of physicians of different medical specialties regarding the use of chaperones in their daily clinical practice.

\section{Methods}

Using a structured questionnaire, the researchers have in this work, aggregated data from tertiary health care institutions in Nigeria and statistically analysed the knowledge and attitude of chaperoning by physicians (Consultants and Senior registrars) who attend to patients in various clinics. Necessary ethics committee approval was secured for the study reported and was sought and granted by study hospital's Ethical Committee.

A structured questionnaire was self-administered to all the consenting doctors seen at the various outpatient clinics of the four tertiary hospitals (Nnamdi Azikiwe University Teaching Hospital, Nnewi; University of Nigeria Teaching Hospital, Ituku-Ozalla, Enugu; Chukwuemeka Odumegwu Ojukwu University Teaching Hospital, Awka and Federal Teaching Hospital, Abakaliki) over a 3-month-period. The questionnaire was pilot-tested by 10 consultants at one tertiary hospital who were asked to comment on the clarity of the questions and to note any information missing from the questionnaire that they felt should be included. Main outcome measures include: frequency of chaperone use, views on mandatory chaperone use policy, preferred gender for the role of chaperone and main factors influencing the physicians' attitude.

A power calculation was done using a previous study in Nigeria of 35.9\% of male gynaecologists always or often using chaperones, which showed that a sample size of 167 subjects had an $80 \%$ power at a 5\% type 1 error with a 10\% attrition/non response rate [11].

The data collected was recorded and analysed using Statistical Package for Social Sciences (SPSS) Statistical software version 18. The percentages were calculated on the number who answered any given question. A descriptive analysis was undertaken of the physicians' demographic data and their responses to the survey questions. Bivariate analyses were conducted using the chi-squared test and t-test as appropriate. A p-value of 0.05 or less was considered statistically significant.

\section{Results}

Of the 200 questionnaires distributed, 150 were returned for a response rate of $75.0 \%$. Twenty-five of the returned questionnaires were excluded from the analysis because the respondents were not specialist physicians, thereby yielding a final achieved sample of 125. Thus, only 125 of them were analysable.

The final sample appears to be representative of the target survey population. As shown in Table 1, the age distribution of respondents shows that $76.0 \%(95 / 125)$ of the respondents were 30 years and above.

\begin{tabular}{|c|c|}
\hline Physician characteristics & Frequency (\%) \\
\hline \multicolumn{2}{|c|}{ Gender } \\
\hline Male & $95(76.0 \%)$ \\
\hline Female & $30(24.0 \%)$ \\
\hline \multicolumn{2}{|c|}{ Age groups } \\
\hline 329 & $30(24.0 \%)$ \\
\hline $40-39$ & $73(58.4 \%)$ \\
\hline$\geq 50$ & $19(15.2 \%)$ \\
\hline \multicolumn{2}{|c|}{ Specialty } \\
\hline Surgery & $3(2.4 \%)$ \\
\hline Gynecology & $27(21.6 \%)$ \\
\hline Internal medicine & $29(20.8 \%)$ \\
\hline General practice & $36(28.8 \%)$ \\
\hline
\end{tabular}




\begin{tabular}{|c|c|}
\hline Physician characteristics & Frequency (\%) \\
\hline Paediatrics & $7(5.6 \%)$ \\
\hline \multicolumn{2}{|c|}{ Years in service } \\
\hline $1-5$ & $96(76.8 \%)$ \\
\hline $6-10$ & $22(17.6 \%)$ \\
\hline $11-15$ & $5(4.0 \%)$ \\
\hline$\geq 16$ & $2(1.6 \%)$ \\
\hline
\end{tabular}

Table 1: Socio-demographic distribution of the respondents

With the exception of paediatrics, 5.6\% (7/125), all other specialty were homogeneously represented. Of the 125 respondents, 95 (76.0\%) were males and $30(24.0 \%)$ were females. The relationship between socio-demographic variables and attitudes of physicians to chaperone policy in medical practice is shown in Table 2.

\begin{tabular}{|c|c|c|c|c|}
\hline $\begin{array}{c}\text { Physicians } \\
\text { characteristics }\end{array}$ & Yes (\%) & No (\%) & $\begin{array}{l}\text { Pearson } \\
\text { Chi-square }\end{array}$ & P-value \\
\hline \multicolumn{5}{|c|}{ Gender } \\
\hline Male & $90(72.0 \%)$ & $2(1.6 \%)$ & \multirow{2}{*}{1.10} & \multirow{2}{*}{0.577} \\
\hline Female & $29(23.2 \%)$ & $1(0.8 \%)$ & & \\
\hline \multicolumn{5}{|c|}{ Age groups (years) } \\
\hline$\leq 29$ & $29(23.2 \%)$ & 0 & \multirow{4}{*}{18.52} & \multirow{4}{*}{0.005} \\
\hline $30-39$ & $72(57.6 \%)$ & 0 & & \\
\hline $40-49$ & $15(12.0 \%)$ & $3(2.4 \%)$ & & \\
\hline$\geq 50$ & $3(2.4 \%)$ & 0 & & \\
\hline \multicolumn{5}{|c|}{ Specialty } \\
\hline Surgery & $27(21.6 \%)$ & 0 & \multirow{5}{*}{8.97} & \multirow{5}{*}{0.345} \\
\hline Gynaecology & $25(20.0 \%)$ & $1(0.8 \%)$ & & \\
\hline $\begin{array}{l}\text { Internal } \\
\text { medicine }\end{array}$ & $28(22.4 \%)$ & $1(0.8 \%)$ & & \\
\hline $\begin{array}{l}\text { General } \\
\text { practice }\end{array}$ & $33(26.4 \%)$ & $1(0.8 \%)$ & & \\
\hline Paediatrics & $6(4.8 \%)$ & 0 & & \\
\hline \multicolumn{5}{|c|}{ Years in service } \\
\hline $1-5$ & $90(72.0 \%)$ & $3(2.4 \%)$ & \multirow{4}{*}{1.90} & \multirow{4}{*}{0.928} \\
\hline 6-10 & $22(17.6 \%)$ & 0 & & \\
\hline $11-15$ & $5(4.0 \%)$ & 0 & & \\
\hline$\geq 16$ & $2(1.6 \%)$ & 0 & & \\
\hline
\end{tabular}

$\%=$ percentage

Table 2: Relationship between socio-demographic variables and attitudes of physicians to chaperone policy in medical practice

Bivariate analysis identified only one variable (age) to be significantly associated with the use of chaperones by physicians in the study. Regarding the various views of the respondents towards recommendation of mandatory chaperone policy in the physicians' health care institution, $74.4 \%$ (93/125) agreed, $12.0 \%$ (15/125) did not agreed while 13.6\% (17/125) were undecided. There is no statistically significant difference ( $\mathrm{p}>0.05)$ when subjected to the demographic variables.

Table 3 shows the respondents' frequency of use of chaperone, whiles the relationships between various variables/factors and respondents' frequency of use of chaperone and chaperone policy is shown in Table 4.

With regard to the frequency of use of chaperone by physicians, there is no statistically significant difference with regard to gender, age and number of years of practice as physicians ( $p>0.05)$. However, $24.0 \%(30 / 125)$ of the males always or frequently use chaperone as opposed to $16.8 \%(21 / 125)$ of the female physicians. Majority, $49.2 \%(59 / 120)$ preferred cross gender policy followed by male doctor to female patient in $35.8 \%(43 / 120)$. 


\begin{tabular}{|c|c|c|c|c|c|}
\hline Characteristics & Never (\%) & $\begin{array}{c}\text { Occasionally } \\
(\%)\end{array}$ & $\begin{array}{c}\text { Frequently } \\
(\%)\end{array}$ & Always (\%) & P-value \\
\hline \multicolumn{6}{|c|}{ Gender } \\
\hline Male (n=91) & $9(10.0 \%)$ & $58(63.7)$ & $17(18.6)$ & $7(7.7)$ & \multirow{2}{*}{ NS } \\
\hline Female $(n=30)$ & $7(23.3 \%)$ & $18(60.0)$ & $3(10.0)$ & $2(6.7)$ & \\
\hline \multicolumn{6}{|c|}{ Age (years) } \\
\hline $20-29(n=30)$ & $7(23.3 \%)$ & $20(66.7)$ & $20(66.7)$ & $1(3.3)$ & \multirow{4}{*}{ NS } \\
\hline $30-39(n=71)$ & $9(12.7 \%)$ & $40(56.3)$ & $40(56.3)$ & $8(11.3)$ & \\
\hline $40-49(n=17)$ & 0 & $14(82.4)$ & $14(82.4)$ & 0 & \\
\hline $50-59(n=3)$ & 0 & $2(66.7)$ & $2(66.7)$ & 0 & \\
\hline \multicolumn{6}{|c|}{ Years in service } \\
\hline $1-5(n=94)$ & $15(16.0)$ & $59(62.8)$ & $13(13.8)$ & $7(7.4)$ & \multirow{4}{*}{ NS } \\
\hline $6-10(n=20)$ & $1(5.0)$ & $13(65.0)$ & $4(20.0)$ & $2(10.0)$ & \\
\hline $11-15(n=5)$ & 0 & $4(80.0)$ & $1(20.0)$ & 0 & \\
\hline $16 \&$ above $(n=2)$ & 0 & 0 & $2(100.0)$ & 0 & \\
\hline
\end{tabular}

NS=Not significant; \%=percentage

Table 3: Frequency of use of chaperone by the respondent

\begin{tabular}{|c|c|}
\hline Response & Frequency (\%) \\
\hline \multicolumn{2}{|c|}{$\begin{array}{l}\text { i. Frequency of use of chaperone and chaperone policy } \\
\qquad(n=77 ; \text { no response, } n=48) \text { : }\end{array}$} \\
\hline Never & $1(1.3)$ \\
\hline Occasionally & $53(68.8)$ \\
\hline Frequently & $13(16.9)$ \\
\hline Always & $9(11.7)$ \\
\hline Can’t remember & $1(1.3)$ \\
\hline \multicolumn{2}{|c|}{$\begin{array}{l}\text { ii. When you use a chaperone, do you record in patients' } \\
\text { note the name and position of chaperone used? }(n=125)\end{array}$} \\
\hline Yes & $10(8.0)$ \\
\hline No & $107(85.6)$ \\
\hline Occasionally & $5(4.0)$ \\
\hline Can't remember & $3(2.4)$ \\
\hline \multicolumn{2}{|c|}{$\begin{array}{l}\text { iii. Should a patient choose whether or not s/he want a } \\
\text { chaperone? }(n=119 ; \text { no response, } n=6)\end{array}$} \\
\hline Yes & $56(47.1)$ \\
\hline No & $53(44.5)$ \\
\hline Indifference & $10(8.4)$ \\
\hline \multicolumn{2}{|c|}{$\begin{array}{l}\text { iv. Have you found the presence of chaperone useful in } \\
\text { your practice? }(n=118 \text {; no response, } n=7)\end{array}$} \\
\hline Yes & $87(73.7)$ \\
\hline No & $5(4.2)$ \\
\hline Occasionally & $15(12.7)$ \\
\hline Don't know & $11(9.3)$ \\
\hline \multicolumn{2}{|c|}{$\begin{array}{l}\text { v. Do you recommend gender specific chaperone ? }(\mathrm{n}=115 \\
\text { no response, } \mathrm{n}=10)\end{array}$} \\
\hline Yes & $92(80.0)$ \\
\hline No & $5(4.3)$ \\
\hline Don't know & 18(15.7) \\
\hline
\end{tabular}




\begin{tabular}{l|c|c|}
\hline \multicolumn{1}{|c|}{ Response } & Frequency (\%) \\
\hline $\begin{array}{c}\text { vi. If you recommend gender specific chaperone policy, what } \\
\text { gender combination? ( } \mathrm{n}=120 \text {; no response, } \mathrm{n}=5)\end{array}$ \\
\hline Male doctor to female patient & $43(35.8)$ \\
\hline Female doctor to male patient & $1(0.8)$ \\
\hline Female doctor to female patient & $6(5.0)$ \\
\hline Male doctor to male patient & $1(0.8)$ \\
\hline 3 and 4 above & $10(8.3)$ \\
\hline Cross gender & $59(49.2)$ \\
\hline vii. If you prefer exam-specific policy, which body part you want \\
examined in presence of chaperone (n=125)
\end{tabular}

\section{Discussion}

This study is the first step in understanding the attitudes and experiences of physicians practicing in Nigeria towards the use of chaperones in daily clinical practice. We could not find any published research that pertains to the Nigerian physician general daily practice setting on the use of chaperone. The results of this survey indicate that more than $70 \%$ of the physicians recommend mandatory chaperone policy in clinical practice. This is in keeping with the recommendations of many major medical associations and medico-legal societies [11-13].

Quite surprisingly, more than 70\% of the physicians either had never or occasionally used a chaperone in their practice, despite the greater number agreeing that the presence of chaperone had been useful in their practice. By extrapolation, chaperones are used in only a minority $(<30 \%)$ of clinical examinations performed by physicians in study hospitals. This finding agrees with previous study in South Africa, Australia and in Norfolk [14-16]. In these studies, although only a minority of practitioners offered chaperones to patients, many still felt that they are important for medico-legal reasons and as a legal support for the patient. Therefore, best practice may favour mandatory offer of chaperone. This will provide patients with choice and offer the practitioners some level of protection.

Although one study documented increased chaperone use, many previous studies have reported varying rates of low levels of chaperone use by physicians for various reasons [17]. For example, in a previous study of chaperones in Nigeria, Nkwo, et al. found that most Nigerian gynaecologists use chaperones at least some of the time and also support a policy of routinely offering chaperones during intimate gynaecologic examination while respecting patients' right to decline this offer [11]. It seems inappropriate that up to $70 \%$ of physicians do not use chaperones in their daily clinical practice.

Previous studies have indicated that the sex of the examining physician consistently influences women's preferences for a chaperone with more women preferring a chaperone in the presence of a male physician $[18,19]$. This is in keeping with our findings with proportionately more males $(24.0 \%)$ using chaperone than female physicians $(16.8 \%)$. According to our findings, the use of chaperones varies greatly by type of examination with the whole body as well as pelvic and breast examinations the most likely to be observed by a chaperone. This was corroborated by previous published studies $[6,15]$. Using a chaperone has been shown to add both a layer of protection and acknowledgement of a patient's vulnerability $[9,15]$.

In contrast to general belief, the use of chaperones correlated with physicians' age $(\mathrm{p}<0.05)$ but years of practice had no correlation. The reasons for this are quite inexplicable. However, our study captured only specialist doctors within 5 years of clinical practice and it is not impossible that the association may differ if our data included older practitioners. However, other previous studies did not report any age-related differences $[6,13,15,17]$.

Quite surprising, the majority (49.2\%) of the physicians preferred cross gender policy followed by male doctor to female patient policy (35.8\%). This is so because, in a previous study in Nigeria by Nkwo, et al. involving exclusively the attitudes of gynaecologist towards chaperone use in clinical practice, $35.9 \%$ of male gynaecologist always or often used chaperones, while $76.9 \%$ of female gynaecologist used chaperones only under special circumstances [11]. No female gynaecologist was reported to always or often used a chaperone during pelvic examination [11]. However, the defense organizations strongly advise that both female and male doctors should always use chaperone during clinical consultations. 
There are potential limitations to this study. Firstly, physician attitude was self-reported and therefore may not be a true reflection of their actual practice. At the same time, however, our questionnaire was entirely anonymous and response is purely voluntary, so this may influence the response as respondents could not be traced to confirm their submissions. Secondly, although a response rate of $75 \%$ is now considered high for a physician survey, we could not completely exclude the possibility of non-response bias. It is really surprising that there is actually relatively low actual use of chaperone in Nigeria as shown in this study. The reasons for this need further exploration and are subject to future study.

\section{Conclusion}

This is the first step in understanding attitudes and current practices of physicians in Nigeria towards mandatory use of chaperone in clinical practice. Although, most of the physicians either had never or occasionally used a chaperone in their practice, the greater number agreed that the presence of chaperone had been useful in their practice. In the end, majority of the physicians preferred cross gender policy and the use of chaperones appear to be correlated with physicians' age. Further study involving a larger and national study is needed to help further $\mathrm{x}$-ray this vital chaperoning issue with a view to determining suitable and practicable chaperone policy.

\section{Acknowledgement}

We are indebted of all the physicians who took time out of their busy schedules to participate in our survey - without their contribution, this study would not have been a success.

\section{Reference}

1. Jones K, Biezen R, Beovich B, van Hercke O (2015) Chaperones for intimate examinations in family medicine: findings from a pilot study in Melbourne, Australia. Med Sci Law 55: 6-10.

2. Van Hecke O, Jones KM (2012) The Attitudes and Practices of General Practitioners about the Use of Chaperones in Melbourne, Australia. Int J Family Med 2012: 768461.

3. Nkwo PO, Chigbu CO, Nweze S, Okoro OS, Ajah LO (2013) Presence of chaperones during pelvic examinations in southeast Nigeria: Women's opinions, attitude, and preferences. Niger J Clin Pract 16: 458-61.

4. Royal College of Nursing (2006) Chaperoning: The role of the nurse and the right of the patient. Guidance for nursing staff. London. RCN 001446.

5. Royal College of Obstetricians and Gynaecologists (2002) Gynaecological Examinations: Guidelines for Specialist Practice. RCOG Press.

6. Price DH, Tracy CS, Upshur RE (2005) Chaperone use during intimate examinations in primary care: postal survey of family physicians. BMC Fam Pract 6: 52. 7. Department of Health (2004) Independent Investigation Into How The NHS Handled Allegations About The Conduct Of Clifford Ayling. Committee of Inquiry 278.

8. Kurpad SS, Machado T, Galgali RB (2010) Is there an elephant in the room? Boundary violations in the doctor patient relationship in India. Indian J Med Ethics 7: $76-81$

9. Rogstad KE (2007) Chaperones: protecting the patient or protecting the doctor? Sex Health 4: 85-7.

10. Sinha S, De A, Jones N, Jones M, Williams RJ, et al. (2009) Patients' attitude towards the use of a chaperone in breast examination. Ann R Coll Surg Engl 91: 46-9.

11. Nkwo PO, Chigbu CO, Ajah LO, Okoro OS (2013) The perception and use of chaperones by Nigerian gynecologists. Int J Gynaecol Obstet 120: 46-8.

12. Obionu CN (1998) The use of chaperones by general practitioners in Nigeria. Trop Doct 28: 56-7.

13. Johnson NR, Philipson EH, Curry SL (1999) Chaperone use by obstetrician/gynecologists. J Reprod Med 44: 423-7.

14. Guidozzi Y, Gardner J, Dhai A (2012) Professionalism in the intimate examination: how healthcare practitioners feel about having chaperones present during an intimate consultation and examination. S Afr Med J 103: 25-7.

15. Newton DC, Fairley CK, Teague R, Donovan B, Bowden FJ, et al. (2007) Australian sexual health practitioners' use of chaperones for genital examinations: a survey of attitudes and practice. Sex Health 4: 95-7.

16. Conway S, Harvey I (2005) Use and offering of chaperones by general practitioners: postal questionnaire survey in Norfolk. BMJ 330: 235-6.

17. Sinha S, De A, Williams RJ, Vaughan-Williams E (2010) Use of a chaperone during breast examination: the attitude and practice of consultant breast surgeons in the United Kingdom. Scott Med J 55: 24-6.

18. Penn MA, Bourguet CC (1992) Patients' attitude regarding chaperone during physical examinations. J Fam Pract 35: 639-43.

19. Al-Gaai EA, Hammami MM (2009) Medical chaperoning at a tertiary care hospital in Saudi Arabia: survey of physicians. J Med Ethics 35: 729-32. 


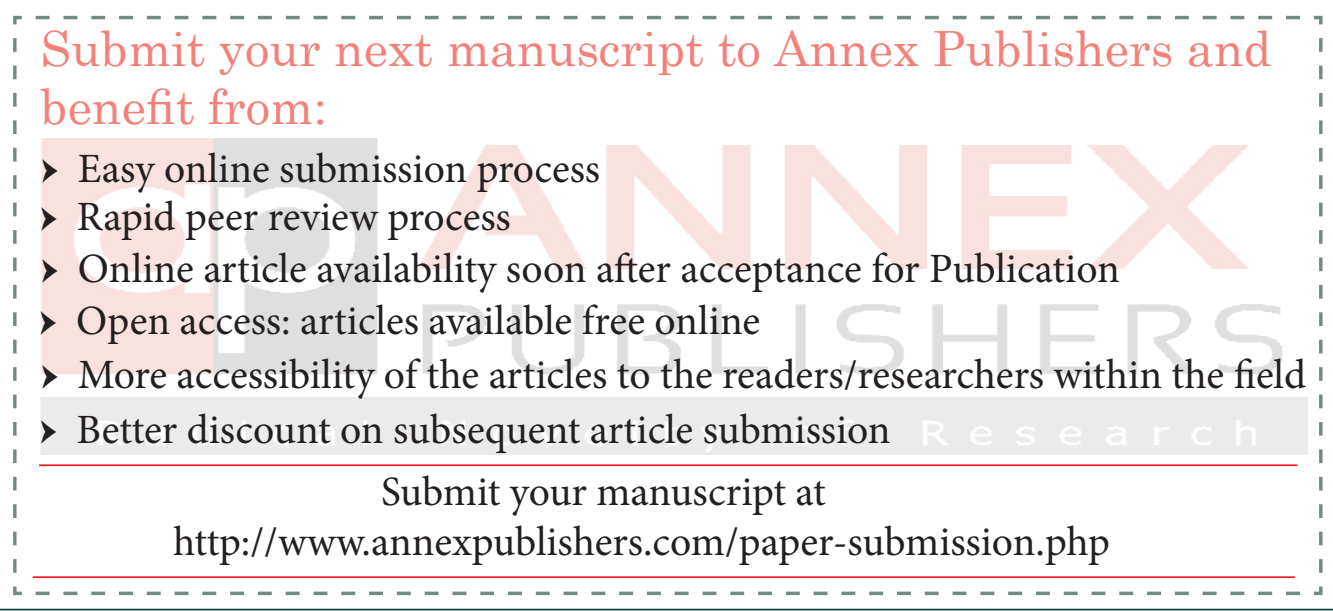

